\title{
The evolution of surgical mentorship, or 10 pounds of potatoes in a 5-pound bag
}

\author{
Keith S. Naunheim, MD
}

\author{
From the Division of Thoracic Surgery, St. Louis University, St. Louis, Mo. \\ Disclosures: Author has nothing to disclose with regard to commercial support. \\ Received for publication Oct 28, 2015; accepted for publication Oct 28, 2015; available ahead of print Nov 24, \\ 2015. \\ Address for reprints: Keith S. Naunheim, MD, Thoracic Surgery, St. Louis University, 3635 Vista Ave at Grand \\ Blvd, St. Louis, MO 63110 (E-mail: naunheim@slu.edu). \\ J Thorac Cardiovasc Surg 2016;151:645-6 \\ $0022-5223 / \$ 36.00$ \\ Copyright (C) 2016 by The American Association for Thoracic Surgery \\ http://dx.doi.org/10.1016/j.jtcvs.2015.10.109
}

Although the mentor-mentee relationship has been a vital connection in surgical education for many decades, it has rarely been dissected and analyzed with the level of detail as that demonstrated by Tsai and Helser. In their paper they endeavor to systematize and delineate the "duties" of a surgical mentee in detail, in hopes that a more clear description and understanding of this professional dynamic will allow the surgical trainee to optimize his or her own personal mentorial relationship. Interestingly, an article penned by Michael Pasque was published in the October issue of the Journal ${ }^{1}$ and it examined this same educational dynamic from the obverse perspective, that of the mentor. Together, these 2 papers provide an important contribution to our understanding of surgical education as it has evolved in the 21 st century.

For those thoracic surgeons approaching and beyond Medicare age, our mentor-mentee relationship was somewhat less demanding and far less defined than that described in these papers. It was an easier time in surgical education for many reasons. For instance, we only had to learn to do a given operation one way, rather than having to master an open and then a minimally invasive and then a robotic approach. Work hour limitations were nonexistent, allowing for significantly greater clinical exposure and experience during residency. Patients were generally younger with fewer comorbid conditions, both of which provided a clinical "cushion," such that less than technically perfect operative results could still yield a clinical success.

Back then, just as today, failures inevitably occurred. But while there was appropriate educational feedback regarding missteps, there was little or no fear of public shaming or retribution owing to scrutiny by a media outlet or regulatory agency. Because such scrutiny was not routine, significantly more autonomy was granted, and our opportunities for independent operative experience far exceeded those of today's residents. At the risk of sounding maudlin, it was indeed a simpler time.

For all of these reasons, the mentorial relationship was somewhat more simple and less demanding. Residents

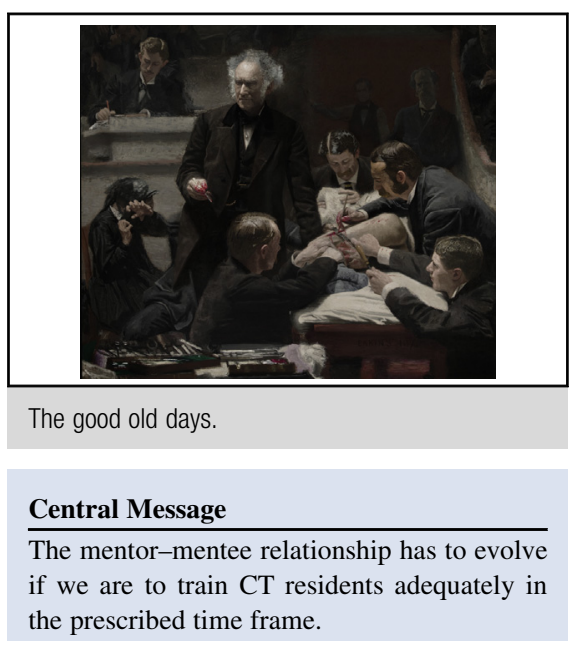

See Editorial page 642 .

were allowed and expected to learn on their own. If you inquired where to look for the curriculum, you would get a funny look and then be instructed to "read the damn textbook." In the operating theater, a significant portion of our education was attained using the classic SODOTO (see one do one teach one) training methodology. A certain amount of trial, error, and failure was not only acceptable, but expected. The main roles of the mentor were to provide teaching cases, give guidance on perioperative and intraoperative care (sometimes from a distance), and assist the trainee both in career selection and in finding a posttraining position. In short, both mentor and mentee had less proscribed and arduous roles within the old system.

Fast forward to 2015. Both the mentor and the mentee face new and serious obstacles to their common goal of resident education. Training both in and outside of the operating room has become exponentially more difficult owing to multiple changes in the practice of surgery, as well as in society as a whole. Today's trainees are allowed fewer hours in the hospital and yet are expected to master an ever-expanding volume of surgical knowledge that far surpasses that required of their elders. Independent operating has been curtailed markedly, because few if any mistakes are allowable; extremes of patient age and fragility mandate a "perfect" operation, which may preclude trainee involvement owing to the inherent learning curve. Similarly, ongoing public scrutiny of outcomes makes it difficult to allow residents the operative independence they need to polish their technical skills. 
Because the rapid and ongoing advances in technology have produced an ever-evolving landscape of procedures and techniques, many senior surgeons are asked to teach skills they themselves may have acquired only recently (eg, endovascular procedures, robotic surgery) and have yet to truly master. Finally, attendings are asked to instruct trainees in activities that they themselves never learned (eg, simulation labs) or perhaps don't even approve of (eg, "team care concept" with tag team postoperative coverage). For all of these reasons, successful cardiothoracic surgical training has never been more difficult to achieve.

What has not changed is the goal of the relationship: to prepare the trainee for the independent practice of cardiothoracic surgery. Recognizing that changes in cardiothoracic surgery practice and in society have made this endeavor more difficult, a more focused, deliberate effort on the part of both mentor and mentee is needed. This is certainly true for the standard 7- or 8-year general surgery-thoracic surgery training track, but is perhaps even more critical in the integrated 6-year residency, which further curtails the available time for training.

That is why these 2 papers are so important and should be required reading for all trainees and faculty. They describe the specific roles and activities in which both participants must actively engage if our training programs are to produce mature surgeons, capable of the technical and cognitive performance required for the successful practice of thoracic surgery. Failure to achieve such complete and active engagement will likely result in the graduation of young surgeons ill-prepared for independent thoracic surgical practice. That would be a failure not only for the trainees but also for society as a whole.

\section{Reference}

1. Pasque MK. Extreme mentoring in cardiothoracic surgery. J Thorac Cardiovasc Surg. 2015;150:785-9. 